\title{
Enhancing the International Advisory Service at the University of Edinburgh
}

Kim Pearson, University of Edinburgh

\section{Acknowledgement}

This paper originated as a student project from the Post Graduate Certificate in Enhancing the International Student Experience.

Introduction from Dr Dave Burnapp (Course Leader)

This article describes a series of inter-related activities being trialed by the visa advisory team at Edinburgh University in a time of rapid expansion of recruitment of international students and of great flux in governmental visa policy. In order to better serve this growing demand the team are exploring improved web-based material using the virtual learning environments which the students are familiar with. This is balanced with face-to-face interventions in workshop groups as well as individual counseling, reflecting the different expectations of students from different cultures.

\section{Abstract}

The University of Edinburgh has a long-standing reputation as a globally recognized institution; having been at the forefront of international education since its founding in 1583. In recent years the University has striven to retain a strong position in the global arena, in terms of research, quality and accessibility of education and overall international influence. The University's internationalization strategy sets out a plan to maintain the institution's global standing, but also proposes a number of long-term aims. These include increasing the number of international students as well as facilitating globalization by embedding it in the ethos of the institution; something which is certainly of crucial importance in today's multinational society (University of Edinburgh, 2009).

Keywords: international students; electronic student support 


\section{Research Aims}

The University's visa advisory team forms part of the international office; its main remit being to help students apply for a study visa to enter or remain in the UK. Our office has three international student advisors, including myself and a student support assistant. Over the past five years, the demand for immigration advice has grown drastically, which can be accounted for by a number of factors. This is firstly due to a sharp rise in the overall number of international students, in line with the aims of the University's internationalization policy. Another reason for the increased demand for visa advice is because of governmental policy changes and the overhauling of the UK's immigration system.

In March 2009, the UK Border Agency (UKBA) began the first phase of implementing the Points-Based System (PBS). This is a visa system based on the Australian model, which is more complex than the route which was previously in place. PBS aims to eradicate discretion of caseworkers in deciding the outcome of visa applications and hence, tighten up on the flow of migrants into the UK. Where the previous system allowed for a margin of error and was more 'user-friendly', PBS is based on meeting set criteria and does not allow for discrepancies.

We found that after the introduction of PBS, our service suddenly became inundated with queries from students who had had their visa extension applications rejected after applying independently to the UKBA. The volume of appointments began to rise to the point where it was becoming increasingly difficult to manage the service effectively. Student feedback, which we collated from e-mail enquiries, individual appointments and the international-graduate survey results of the following year, was demanding an intervention into the provision of immigration help and advice offered by our team.

As we began to research ways of amending our service to meet the increased need for visa advice, we were aware that we would have to manage student expectations accurately to fit in with our capacity as a team. Throughout the procedure, we have taken into account the comments and feedback of students who used our service. We also referred closely to the bi-annual results of the international-graduate survey, which we use as a benchmarking tool for service provision within the Higher Education sector. Immigration advice is regulated by the Office of the Immigration Services Commissioner (OISC) and given the legal requirement for client confidentiality, we felt it would be unethical to conduct independent surveys or explicit student led research.

We aimed to look at various ways in which to make our service more useful and informative to both staff and students. We planned to improve web-based material available to students, making relevant visa information more readily accessible to them through channels that they utilize in their day to day lives. We planned to do this by making use of available technology, such as virtual learning environments and other similar interactive media. We also considered ways of amending our current service, relating to the way we run visa workshops and handle immigration appointments. 
The idea of operating a more virtually reliant service, cutting down on face-to-face appointment time could be seen as creating a somewhat 'arm's length' approach to the visa advice we give. However, the reason for this is mainly so that students will be more informed and prepared in relation to their immigration status before seeing an advisor. This should not only free-up time for our team to concentrate on other essential aspects of our work, but will also place the onus back onto the student, who is ultimately responsible for their visa application and for taking into account the necessary timeframe to prepare supporting documentation. Our web-based resources also form another key aspect of our service, given that we help students apply for study visas from abroad. As we cannot physically see these students and have very little or no influence in the decisions made by the British Consulates and High Commissions outside of the UK, it is essential that the students are well informed and aptly prepared before applying for a visa. Many of our post graduate students bring their dependant family members to the UK to live with them and also require help with their visa applications. In addition to this, Edinburgh University attracts a number of visiting scholars and post-doctoral researchers from around the world. It is therefore of key importance that our online immigration information is accurate, up-to-date and user friendly.

\section{Literature Review}

Although there does not currently appear to be much discourse available which specifically targets support services for international students, an ever increasing number of publications are surfacing which relate to the drive towards internationalizing higher education institutions. This trend can be found in government policies and initiatives, as well as in larger and smaller scale academic reports and surveys. Often these relate more broadly to the support sector, which despite this makes up an integral component in easing the transition towards the globalization of HEIs. The lack of available literature specifically relating to immigration advice could be due to aforementioned regulatory codes of practice and ethics. The available literature was therefore referred to in order to help make more general improvements to our overall service provision.

Kelo (2007, p.174) believes that: 'A general 'service mentality', that is the recognition of the importance of student support in general, and especially for international students, is more widely spread in some countries than others. The overall approach to services within an institution seems to have a strong impact on the institution's sensitivity towards international students, and on the willingness to consider offering special services to them.'

This increased need for student support was the issue that had prompted us to look at ways of amending our service to accommodate the greater demand in expectation from our students. Some literature suggests offering focus groups for international students, specifically targeting differences in cultural perceptions of services expected from education providers (UKCISA, 2009, p.4). It seems that this 'service mentality' is indeed something which the UK is moving towards, given the impetus from Universities for the provision of a global educational experience as a marketing point 
for higher education. Worryingly, a UKCOSA survey (2007, p.2) pointed out the absence in correlation between the number of international students and the number of international student advisors in institutions. UKCOSA states that 'anecdotal feedback to UKCOSA over a long period suggests that in many cases institutional management does not provide the resources needed for specialist advice provision to increase in line with the number of students.' UKCOSA (ibid), does however suggest that this 'should not prevent institutions from looking internally for indicators of whether advice services have the resources needed to adequately support international students'. In our case, we would explore the use of technology to bring our service to more students.

Although management within institutions can look at support services available to international students and may well recognize a shortage of staff in relation to the number of students, it is often not financially viable to rectify this. It is too often the case, as Kelo (2007, p.175) points out that 'support for international students lies thus on the good will and interest of individual staff members'. On a more positive note, Edinburgh University's international-graduate survey results for the academic year 2009-10 showed that $83.7 \%$ of students were satisfied with the visa advisory service provided by the international office (Edinburgh University ISB results, summer 2010). This was a marked increase from previous years and an indication from our student voice that changes made to the service were having a positive impact on international students.

\section{Outline of intervention}

Despite the high student satisfaction levels, we felt that there were various aspects of our service which could be improved and not least to cut down on the amount of time each advisor spent with individual students. The timescale in which our planned changes were to take place were of prime importance and needed to be played out around the peak times of year for visa enquiries and the intake periods of new international students. We operate the student Batch scheme, which means that the advisors are responsible for checking and sending student visa applications to the Home Office on behalf of the students. This creates a considerable amount of work for our team, especially in regard to filling out paperwork and filing documents. There are however, a number of advantages in using the Batch scheme, which we feel outweigh any disadvantages. These are mainly to do with the fact that we have control over what the visa applications contain and can liaise a lot more easily with caseworkers in the Home Office than we could if the student were to send a visa application themselves (Batch scheme user group, 2010). The fact that we operate the scheme means that we have very specific peaks and troughs in service demand. This is largely due to students having similar visa expiry dates, meaning that most student visas need to be extended in October, November, and February. Often these dates fall in line with course end dates and surges in visa applications are most noticeable shortly after the final submission and end dates of particular courses.

We therefore chose to start implementing our changes in July, August and early December. In July we had a number of meetings, sometimes with other staff members to discuss aspects of the service which we felt needed improvement. Our main concern was that we were spending too much time helping individual students make visa 
applications, meaning that other students were struggling to get appointments with us. We wanted to provide a service which was more wide-ranging and available to a greater number of students, rather than one which could only cope with a small number of students and which was very labour intensive and time consuming. Traditionally we operated an appointment-only service, which normally took place Monday to Thursday, throughout the day in half hour slots during peak times and mornings only when there was less demand. Often students had to see an advisor a number of times before their application was sent to the Home Office, as vital supporting documents would be missing and students had problems filling out the visa application forms. We also ran visa workshops three times a week where an advisor would explain the visa application process, forms and necessary documentation needed to the students present. These workshops were for student and Post-Study Work visa applications and generally had a small capacity due to the size of available rooms.

We decided that one of the main problems was that students were not informed about what was needed to make a visa application when they came to see us. This meant that students often made an appointment a few days before their visa expiry date, expecting the advisor to make the application for them and often not taking any responsibility themselves for missing documents and badly filled out forms. We felt that what was needed was an advertising campaign around the University campuses, alerting students to the necessary timeframes involved in making a successful visa application. This had to be hard hitting and raise awareness of the services provided by the international office to help students. As we were already almost at the beginning of the new academic year, we planned for a poster and flyer campaign to be ready for the academic year 2011-2012, so that it encouraged students to think about what is needed to extend their visa when they first start studying. We also needed to bear in mind the annual publications plan and make sure our campaign was added into the schedule.

In line with this, we are in the process of improving our web-based information and have booked time with the IT support team to make a series of short video clips which will be made available on the University website. These will be in the form of virtual workshops and will also give answers to frequently asked questions. A number of live visa information seminars will be taking place, using software which allows us to create a virtual learning environment with groups of students who are online around the world. This is being advertised throughout the University and to agents abroad in order to encourage prospective students to partake.

In the meantime we planned on using e-mail campaigns and improving our web-based information to target current students whose visas were expiring. The next stage of our planned amendments was to have fewer workshops, but to use lecture theatres so that we could maximise the number of students in attendance. We also felt that students needed to be given information prior to booking a place, which gave details about what the workshop entailed and which documents to prepare. This was suggested by UKCISA (2009, p.9), so that students were made aware of what to expect from the workshop and could accustom themselves to any specialist language used in advance of attending. An information pack was sent to students by e-mail when they booked a place on the workshop. Spaces were booked through the international office reception 
or online. We felt that having bigger workshops and raising awareness of these would mean that students would be a lot more prepared prior to attending a final appointment with an advisor. We also decided to make it compulsory to attend a workshop before having an appointment, so that students could take on more responsibility for their visa applications. We will be running a series of evening workshops to see if more students attend from the campuses which are further away from the central University area.

We also created a number of WebPages for staff, explaining how the visa advisory service works and giving some information about different types of visa, so that staff in the various schools and colleges could be prompted to direct students to the international office if they had visa issues. We are currently discussing a scheme, whereby students could scan their documents and visa application forms to us. This would mean that we would only need to check the original documents and forms, rather than having to then file and scan these ourselves before sending the applications off. This aspect of using the Batch scheme is probably the most time-consuming, but keeping copies of all documents is also a mandatory aspect of the Office of the Immigration Services Commissioner (OISC) compliance (OISC, 2006).

\section{Research methodology}

As indicated initially, it was not possible for us to gather any viable qualitative feedback from individual students who used our service, due to data protection and legal issues around ethics. This makes it difficult to provide a theoretical argument and means that the research methods are mainly based on the above case study of an initiative and subsequent evaluation.

Our research was mainly quantative and the results relate to statistics from the international-graduate survey. In August 2010 we met with Will Archer, founder of the international- graduate survey, to discuss the results relating to our service. We also asked Will to compare this with a range of other services provided by the international office and to look at how well we did in relation to the Russell-group institutions. Questions asked in the international- graduate survey relate to the number of students using the service, how useful they found and help available to them. The results for the visa advisory service were high and generally above the average of the Russell-group institutions, with student satisfaction levels ranging between 83.7-89.3 percent (Edinburgh University ISB results, summer 2010). This showed a marked improvement from previous years, indicating that the changes we had introduced to our service were having a noticeable effect on our international student population.

We also decided to involve relevant staff in other areas of international work to take a fresh look at our overall service provisions. The staff we spoke to were those on reception, who are often the first point of contact for students and the international officers for our two main nationality groups, China and the United States.

We met with reception staff over the summer to discuss proposed changes to our service and to find out what their views and suggestions were. It was suggested that we should also operate a service whereby students could drop into the office to ask basic questions about visas. The reception had found that a number of students did not require a lengthy appointment to send their visa application to the Home Office, but 
simply wanted to ask questions in relation to future visa applications. We decided to include this service in our appointment schedule, so that it would run for one hour, twice a week and students with less complicated questions would be directed to come back during these allocated times to speak to an advisor.

We also set up meetings with the international officers for China and the United States to address specific problems that these student groups had in applying for visas. We had found that over a number of years, general trends had emerged with certain nationalities in relation to issues that students faced. For example, US students often did not expect to need a visa to travel to the UK and would leave it very late to apply or would arrive in the UK and face considerable problems with the UK Border officials. Chinese students often applied for their initial visas using immigration agencies, so when it came to extending their visa in the UK, they struggled to understand the process. We decided that it was essential to make US students aware of the UK visa requirements from the first stage of recruitment and are currently creating an immigration handout, specific to US students, for the international officers to take with them on recruitment visits. We are also looking into translating our online and published information into Chinese to make it more accessible for these students. This is particularly important in relation to supporting documents required for visa extensions, which tend to be in a different format in China.

We also organised a meeting in November 2010 with the association of international student advisors in Scotland to look at how other similar institutions ran their advisory services and to get feedback from other advisors. A senior caseworker from the Home Office was invited to this meeting as well as a member of the UK Border force at Edinburgh airport. We received some useful information from both staff members, notably relating to how prepared international students were generally when entering the UK. According to the airport official, many students were unprepared when they arrived and did not carry any documentation with them to prove that they would be studying during their time in the UK. We felt that by improving our online information and informing students of visas requirements during recruitment trips, we would help to solve this issue.

\section{Findings:}

\section{Workshops and appointments}

We found that we had high numbers of students in attendance when operating larger but fewer workshops, with up to thirty students attending each session during the peak periods. At first some students did not want to attend the workshops as they were working or studying during these times. However, as relatively high numbers were in attendance, this problem was solved fairly quickly through word of mouth from other students and by the reception staff, who made it clear that it was mandatory to attend a workshop. We also created a PowerPoint presentation to use, rather than going through the visa application form manually at the workshops as we had done previously. This did cause some problems as not all available rooms had the resources for this. Interestingly also, some students seemed to find the presentation distracting rather than helpful and found it difficult to listen, watch and write things down at the same time. We are currently re-working the presentation so that it is simply a filled out visa application form, which we can go through step by step. 
We have generally found that students are now more prepared when the come to an individual appointment. Inevitably some students still leave their applications very late. What has been very useful is the workshop information pack, which does mean that if students really cannot attend a workshop, then they can read through this and prepare necessary documents before attending a final appointment. Also, because the number of students attending the workshops has been so high, we have come across quite a few individuals whose classmates have helped them with the visa application process after having attended a workshop. This is obviously not ideal, as they could easily provide the student with incorrect information, but we have found that it has generally helped other students to at least complete the visa application forms before they see an advisor.

\section{Web information}

It was difficult to gauge what was truly essential information to have on the website and what was surplus, as we wanted to engage the audience as much as possible. We have had good feedback from the staff information section of the website, as more and more staff are now involved in some way in the visa application process given recent changes to immigration policy. Of our web information, perhaps the most useful and widely used section was a PDF version of a student visa application form, which we had annotated and added comments to. This was e-mailed to a number of prospective students along with an immigration guide for students and their families which we had compiled. These two pieces of information meant that students were encouraged to read more about the visa application process and cut down on the number of individual enquiries.

We are still in the process of improving and updating the information available to current students on the University's internal website. However, we have come across various constraints in relation to the layout of the website. This means that it is often necessary to follow a number of steps or links to get to the required information. This has caused problems as we wanted to make the available information as transparent and accessible as possible, but is due to the web software and unfortunately cannot be avoided.

\section{Research reflections}

Much of our research and changes are still in the process of being carried out and are ongoing or staggered throughout the academic year. It is clear that some aspects of our service still require a lot of work and that others, such as the workshops, have improved considerably. There are also a number of factors involved in our work which we do not have any control over, such as frequent changes to immigration policy implemented by UK law. The government and the Home Office are currently reviewing the entire immigration system and are in a period of consultation. The results of this could be wide-ranging and affect many of the support services across the University, as the government aims to 'reduce annual net migration to the UK to sustainable levels, in the tens of thousands a year.' (UKBA, 2010, p.6) 
During our research it became apparent that it was necessary to move into the arena of interactive and online support, especially to target younger students, as more and more individuals now rely on web information and computers. The results of last year's igraduate survey showed that students were more likely to trust information they found on the University website than on other websites which contained similar information (i-graduate, summer 2010). At the same time we found it was necessary to be careful not to become too heavily reliant on the internet as a means of providing advice. Many developing countries either do not always have readily available internet access or do not have compatible software to access the relevant information.

Another issue we faced had to do with different cultural expectations of the support services offered by the University. Some nationalities did not like the idea of having to attend a group lecture before being able to see an advisor on an individual basis and felt that part of the service provided should reflect a high level of one-to-one support. We also found that students still struggled to take into account the timeframes involved in making a visa application. Although students are starting to prepare earlier, many still expect to have their visa applications back quickly if they are processed by the international office. This meant that in December we had a very busy month, as students had booked flights home and had not taken into account that their visa applications would take two to three months for the Home Office to process. A lot of our research came back to the issue of trying to manage expectations and making sure that students fully understood various processes within the institution. As Culbertson (2001), rightly pointed out: 'the road to cross cultural understanding will not always be easy. There will be misunderstandings. There will be clashes of priorities and even deep differences of opinion.'

\section{References}

Great Britain. Home Office, UK Border Agency (2010) The student immigration system: a consultation. London, UKBA

I-graduate International Insight (Edinburgh University ISB results, summer 2010) [Online] Available at: http://www.i-graduate.org/student_faq.html (Accessed 13 November 2010). Please note that access to this data is restricted to the University of Edinburgh and copyright to IGI Services Ltd 2010.

Kelo, M. (2007) 'Approaches to Services for International Students', in Jones and Brown (ed.) Internationalising Higher Education. London: Routledge, pp. 174-179

The UK Council for International Student Affairs (UKCISA) (2007) Benchmarking the provisions of Services for International Students in Higher Education Institutions [Online] http://www.ukcisa.org.uk/files/pdf/pmi/benchmarking_report.pdf (accessed $1 / 12 / 2010)$

The UK Council for International Student Affairs (UKCISA) (2009) Transnational Education and the Student Experience: a PMI Student Experience project report. London, UKCISA 
The UK Council for International Student Affairs (UKCISA) (2009) Discussing difference, discovering similarities: a toolkit of learning activities to improve crosscultural exchange between students of different cultural backgrounds. London, UKCISA

Culbertson, H, Southern Nazarene University, Cross cultural understanding milestones (2001) [Online] Available at: http://home.snu.edu/ HCULBERT/path.htm (Accessed 12 December 2010)

University of Edinburgh (2009) Internationalisation Strategy [Online] Available at: http://www.ed.ac.uk/polopoly_fs/1.9821!fileManager/internationalisationstrategy.pdf (Accessed 12 December 2010)

The UK Council for International Student Affairs (UKCISA) (2010) Batch Scheme User group meetings [Online]. Available at:

http://www.ukcisa.org.uk/members/batch_scheme.php\#usergroup (Accessed 10 December 2010)

OISC Code of Standards (2006) [Online] Available at:

http://www.oisc.gov.uk/servefile.aspx?docid=6 (Accessed 10 December 2010)

\section{University of Edinburgh, International Advisory Service web materials:}

Immigration Guide 2010:

http://www.ed.ac.uk/polopoly_fs/1.35122!fileManager/new\%20students\%20immigrati on\%20guidance.pdf

Overview of Advisory Services: http://www.ed.ac.uk/schools-departments/internationaloffice/immigration/current-students/overview

\section{About the author}

Kim Pearson works at the international office in the University of Edinburgh. 